\title{
Natural and Artificial International Languages: a Typosogist's Assessment
}

\author{
Bernard Comrie* \\ University of Southern California
}

\section{Introduction}

For the purposes of this paper, I will make certain assumptions. ${ }^{1} \mathrm{I}$ will assume that it is a good thing that there should be an international language, serving the purpose of communication among the peoples and nations of the world I will further assume that the purpose of an international language is best served by there being a single such language, such that representatives of all the world's peoples and nations who wish to engage in international communication would be able to do so by learning a single international language.

Let me introduce some clarifications as to what this means. Most emphatically, it does not mean that such an international language should replace other existing languages spoken as first languages. It

\footnotetext{
* Linguistics Deportment, University of Southern California Los Angeles CA 90089-1693

1 This paper was prepared for the Symposium "International Language", held at Sejong University, Seoul, in October 1995, and funded by the Korea Foundation. Korean examples illustrating grammatical points are taken or adapted from Sohn (1994); for vocabulary. I have used Jones \& Rhie (1991). I am grateful to Charles Kyungan Kim for help with the Korean data. Esperanto vocabulary has been checked against Wells (1974). The following abbreviations are used: ACC-accusative, DEC- declarative, GEN- genitive, IND- indicative, LOG- logophoric, NOM- nominative, POL- polite, PRO- prospective. PST- past, QUOquotative, SPC- specific, TOP- topic.
} 
is estimated that at present over 6,000 languages are spoken in the world (Grimes 1992: 930). This is an important resource for our understanding of human diversity, and its importance is all the more evident when we recognize that perhaps most of these languages are endangered; indeed, Kraus (1992: 7) estimates that, if present trends continue, $90 \%$ of the languages spoken today will be extinct or moribund a hundred years from now. It is therefore an urgent task for linguists to assist in the preservation of those languages that are in a position to survive, and to document those languages that are unlikely to do so.

In addition, the adoption of an international language does not necessarily mean that the international language would replace existing local or national lingua francas, whether or not they have official status. I am thinking, for instance, of the role of Indonesian among speakers of other languages in Indonesia, of Swahili in East Africa, of Spanish in most of Latin America, or of French in the Francophone states of Africa and elsewhere, Thus, native speakers of a local language in Niger in West Africa would, under the scenario I envisage, continue to speak their native language, continue to speak Hausa (the major trade language of the area) as well as French (the national language of Niger, also giving access to communication with other Francophone states), with the international language being used for broader international contacts. Whether adoption of an international language will lead to the reduction of the role of "intermediate"-level languages between the native language and the international language, only time will tell

For the purposes of this paper, I will compare two candidates for the status of international language, namely English and Esperanto. The choice is determined by practical considerations, with the desire to compare at least one natural language and at least one artificial language. English is the most widespread international language in current use. While almost all statistics on numbers of first-and second-language speakers must be treated with extreme caution, S. Culbert, of the University of Washington, estimates that in mid1993 the total number of first-and second-language speakers of 
English was 470 million, of whom 322million were first-language speakers. 148 million second-language speakers (world almanac...1994: 598). The next language cited with substantial international use across the world is French, with 124 million speakers, including 72 million first-language and 54 secondlanguage speakers. (There are, of course, several languages with more first-and second-language speakers than French, but they are more restricted geographically, e. g. Spanish primarily to Spain and Latin America, Arabic to the Middle East and North Africa, Russian to the former(USSR.) Of course, the practical considerations that lead to the choice of English as the natural language most used as an international language reflect the situation as it is today. A hundred years ago this position would have been occupied by French. A thousand years ago, when international communication reflected regional rather than global networks, the choice of international language would have depended on the region, for instance Latin in western Europe, Chinese in East Asia.

Esperanto is selected as the most successful artificial language, spoken by far more people than speak any other artificial language designed for human international communication. Exact statistics are even more difficult to come by than in the case of most natural languages. Janton (1993: 113-114) notes that there were at least 120,000 members of Esperanto organizations in 1987, and suggests that the number of speakers must range somewhere "between a strict but minimum figure of some 300,000 to a maximum but overgenerous number of some 15 million". Even the overgenerous maximum is, of course, far lower than that for English or French, but the strict but minimum figure still exceeds that for other comparable artificial-language endeavors and makes Esperanto the obvious candidate for comparison with English as a natural language used for international communication.

In the body of this paper, I will compare English and Esperanto as international languages on a number of parameters, concentrating on the kinds of parameters that are interesting to me as a student of linguistic typology, the study of crosslinguistic similarities and 
divergences. In section 2, I examine structural properties of the languages; in section 3, I examine sociological factors. In particular, I will be concerned with the implications of a claim often voiced for Esperanto and against English, namely that Esperanto has the advantage of being less national than English in that Esperanto is not the native or national language of any particular people or nation.

Before embarking on this comparison, I should however declare possible biases. I am a native speaker of English, and this should be taken into account in assessing whether my account of English is unbiased. I have, however, devoted a good part of my life to acquiring and using other languages, mainly other European languages, and I actively keep up my ability to use a number of languages for practical purposes, some also for purposes of lecturing. My basic attitude towards English is that it is very useful; I have no particular desire to propagate the English language, and nearly all of my professional work as a linguist has been on languages other than English. I feel that I can claim for myself at least some degree of freedom from the Anglo-Saxon bias against languages other than English. I am not an Esperantist, and do not share the enthusiasm for Esperanto of those who are members of the movement I have, however, taken the trouble to acquire a basic structural knowledge of the language, which I can read with the aid of a dictionary. I find Esperanto interesting from a linguistic viewpoint I believe my approach is more objective than that of those who are either committed to the movement or who treat it with total neglect. But it will necessarily be for others to assess the level of my bias.

\section{Structural properties}

A claim often made in favor of Esperanto that it is neutral with respect to the various national languages, or more generally the various natural languages of the world, a claim which, at least at first sight, cannot be made for English. Once one turns to the detailed examination of the structure of Esperanto, however, it is far 
from clear that this claim can be maintained. Let us start by examining the vocabulary of Esperanto.

There is, let it be noted, an obvious sense in which the vocabulary of Esperanto is easier to learn than that of English, namely that the derivational morphology of Esperanto is basically regular, while that of English (and of other natural languages) involves a number of idiosyncrasies, including purely suppletive formal relations among semantically related words. Thus, English has a number of ways of forming antonyms, and by and large one has to learn which process applies to which lexical item; in addition, there are many instances where the antonym is simply a distinct lexical item. In Esperanto, by contrast, all antonyms are expressed by the prefix mall-, as can be seen in the examples in (1):

English sincere insincere Esperanto healthy good unhealthy bad sincera malsincera sana malsana bona malbona

But when one looks at the actual forms of the roots used in Esperanto, it becomes clear that Esperanto is just as much a European language as is English. True, it achieves a certain neutrality among European languages by choosing roots from various languages, as is shown in (2), though there is a clear bias towards Romance (75\%), with Germanic (20\%) as the main secondary source (Janton 1993:51).

$\begin{array}{ll}\text { Esperanto } & \text { Source } \\ \text { bona 'good' } & \text { Romance (French bon, Italian buono, Spanish bueno) } \\ \text { fali 'go fall' } & \text { Germanic (English fall, German fallen, Swedish falla) } \\ \text { kaj 'and' } & \text { Greek ka } \\ \text { cu 'whether' } & \text { Polish czy }\end{array}$

But the European influence on Esperanto vocabulary is not just limited to the forms of lexical roots. The semantic distinctions that are made also reflect those semantic distinctions that are made in European languages. A simple comparison between European 
languages on the one hand and Korean on the other will illustrate this. In European languages, it is usual to have a single lexical item with the semantic range of English carry; in particular, this lexical item makes no difference which part of the body is used to carry the object in question. This same feature is found in Esperanto porti to carry'. In Korean, by contrast, as shown in (3), a variety of different verbs must be used as translation equivalents, depending on the body part used to carry the object in question.

$\begin{array}{ll}\text { English } & \text { Esperanto } \\ \text { carry } & \text { porti 'carry; wear' }\end{array}$

\author{
Korean \\ i-ta 'carry on the head' \\ ci-ta 'carry on the back' \\ an-ta 'carry in the arms' \\ mey-ta 'carry on the shoulders' \\ tuka 'carry in the hand' \\ cha-ta 'carry around the waist'
}

Actually, the Esperanto verb porti betrays an even more restricted European influence. In a number of European languages other than English, the same verb is used in the sense of both 'carry' and 'wear', e.g. French porter, German tragen, Russian nosit '. This same semantic range is carried over to Esperanto porti.

A similar bias in favor of European linguistic patterns is found when we turn to grammatical structure. A striking example is shown by the behavior of relative clauses in Esperanto. The relative clause type which I have called the "relative pronoun strategy" is widespread in European languages, but is rare, if not nonexistent, outside Europe (Comrie 1989: 147-153; forthcoming). The characteristics of the relative pronoun strategy are (i) that the relative clause contains a pronoun referring back to the head noun, (ii) that this pronoun is moved to the front of the relative clause, and (iii) that this pronoun is case marked (by means of either morphological case or an adposition, or both). This is what we find in Esperanto example (4), where the relative pronoun kiu-n refers back to the head noun, is preposed within the relative clause (in Esperanto, the direct object normally follows the verb; see section 3), 
and since it is direct object within the relative clause it receives the accusative case inflection- $n$

$\begin{array}{lllll}\text { (4) la letero } & \text { [Khu-n } & \text { mi } & \text { skrib-is] } \\ \text { the letter } & \text { which-ACC } & \text { I } & \text { write-PST } \\ \text { 'the letter that I wrote' } & & & \end{array}$

Of the other kinds of relative clauses found across the world, two are particularly widespread. One is pronoun retention, in which an ordinary pronoun, not preposed, occurs in the relative clause referring back to the head noun, as in example (5) from Persian.

$\begin{array}{lllllll}\text { zan-i } & {[\text { ke }} & \text { Hasan } & \text { be } & \text { u } & \text { sib-i } & \text { dad] } \\ \text { woman-SPC } & \text { that } & \text { Hasan } & \text { to } & \text { She } & \text { Apple-SPC } & \text { give.PST }\end{array}$
'the woman to whom Hasan gave an apple ${ }^{1}$

The other is the so-called gap strategy, in which there is no overt reference to the head noun from within the relative clause. This type is illustrated by example (6) from Korean.

\begin{tabular}{|c|c|c|c|}
\hline $\begin{array}{l}\text { [Minca-ka } \\
\text { Minca-NOM }\end{array}$ & chayk-ul & $\begin{array}{l}\text { Tuli-1] } \\
\text { give-PRO }\end{array}$ & sensayng \\
\hline
\end{tabular}

English occupies an interesting position with respect to relative clauses, since it has, in addition to the Standard Average European relative clause type (as in the English translations to (5) and (6)), the gap type, as in (7).

(7) the shopkeeper [I bought the book from]

In nonstandard English, one even finds pronoun retention, as in (8).

(8) the road [that I don't know where it leads]

Given the range of variation in its relative clause constructions, English actually turns out to be more neutral than Esperanto on this 
particular parameter.

Another claim often made for Esperanto is that it makes finer semantic distinctions than does, for instance, English. Thus, Janton (1993:68) praises Esperanto for making the distinction between (9) and (10), both of which receive the same literal translation in English, although it is, of course, possible to distinguish the two sentences in English by means of a paraphrase, for example he received him as a prince would for (9) and he received him as one would a prince for (10)

$\begin{array}{lllll}\mathrm{Li} & \text { akcept-is } & \text { li-n } & \text { kiel } & \text { princo } \\ \text { he } & \text { Accept-PST } & \text { he-ACC } & \text { as } & \text { prince }\end{array}$

$\begin{array}{lllll}\mathrm{Li} & \text { akcept-is } & \text { li-n } & \text { kiel } & \text { Princo-n } \\ \text { he } & \text { Accept-PST } & \text { he-ACC } & \text { as } & \text { Prince-ACC }\end{array}$

'He received him as a prince.'

A similar claim is voiced by Eco (1993: 354). Another example showing where Esperanto makes a distinction that English does not is (11), where the reflexive possessive adjective sia (accusative: sia$n$ ) indicates clearly that the picture in question is John's; use of the ordinary, nonreflexive third person singular masculine possessive adjective lia (accusative: lia-n) would indicate that it was someone else's picture.

$\begin{array}{llllll}\text { (11) Johano } & \text { Mostr-is } & \text { sia-n } & \text { Bildo-n } & \text { al } & \text { Maria } \\ \text { John } & \text { show-PST } & \text { own-ACC Picture-ACC } & \text { to } & \text { Maria } \\ \text { 'John } & \text { showed his } & \text { picture to Mary } & & \end{array}$

Here, Korean is closer to the expressive power evinced by Esperanto, since Korean can also make explicit that the picture in question is of the subject of the sentence, through the use of (caki) casin, as in $(12)^{2}$.

\footnotetext{
${ }^{2}$ Korean and Esperanto are not, however, exactly parallel. In(12), at least for some speakers of Korean, the nonreflexive third person pronoun ku-uy does not exclude the situation where the
} 
(12)

$\begin{array}{lllll}\begin{array}{l}\text { Yongho-nun } \\ \text { Yongho-TOP }\end{array} & \begin{array}{l}\text { Minca-eykey } \\ \text { Minca-to }\end{array} & \begin{array}{l}\text { (caki) } \\ \text { self }\end{array} & \begin{array}{l}\text { casin-uy } \\ \text { own-GEN }\end{array} & \begin{array}{l}\text { Sacia-ul } \\ \text { picture-ACC }\end{array} \\ \text { poi-ess-eyo } & & & \\ \text { show-PST-POL } & & & \\ \text { 'Yonghoj showed hisj picture to Minca'. } & \end{array}$

However, there are other examples where languages other than Esperanto prove to make semantic distinctions carried by the grammar that are not available to Esperanto. For instance, in Gokana, a language spoken in southeastern Nigeria, it is possible to distinguish the two senses of English he said that he fell, that is whether he was talking about himself failing or about someone else failing (Hyman \& Comrie 1981). If the two subject pronouns are coreferential, then the so-called logophoric suffix $-e$ (or one of its morphophonemic variants) must be added to the verb of the subordinate clause, as in (13); absence of this suffix indicates that the two subjects are noncoreferential, as in (14).

$\begin{array}{llll}\begin{array}{l}\text { aè } \\ \text { he-PST } \\ \text { 'Hei said that hei fell.' }\end{array} & \begin{array}{l}\mathrm{k} \\ \text { saè }\end{array} & \begin{array}{l}\mathrm{d} \\ \text { fall-LOG }\end{array} \\ \begin{array}{l}\text { aè } \\ \text { he-PST } \\ \text { 'Hei said that hej fell.' }\end{array} & \text { hay } & \text { aè } & \mathrm{d} \\ \end{array}$

Esperanto, like English, fails to make this distinction (other than by use of a freer paraphrase), so that (15) is as unclear as its English translation as to whether the referent of the subject of the main clause is talking about himself or about someone else.

picture is Yongho's, whereas in Esperanto the use of lia-n in (11) does exclude the situation where the picture is John's. Thus, these speakers of Korean can indicate coroference, but have no unequivocal way to indicate nonconference; in Esperanto, the choice of Reflexive versus nonreflexive here correlates exactly with that between coreference and lack of coreference. 


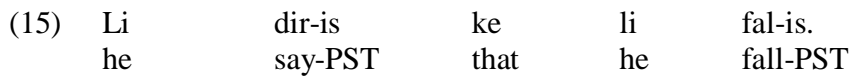

'Hei said that heij fell.'

Korean is also able to make a distinction similar to that of Gokana: In (16), use of the reflexive caki indicates coreference with the subject of the matrix clause. ${ }^{3}$

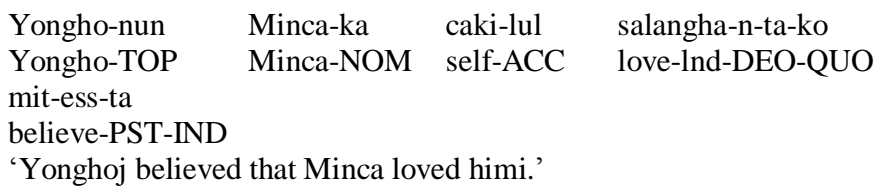

This example of a semantic distinction carried by the grammar that is made in languages other than Esperanto but not in Esperanto stands alongside the parallel lexical example in (3). More generally, for any pair of natural languages, there will also be some semantic distinctions that are made in the one but are not made in the other. One might imagine that an artificial language should be constructed to make all of these semantic distinctions. But even assuming that the list of such distinctions is both finite and ascertainable-after all, there are surely semantic distinctions that could be made in natural language but happen not to be made known or available to us-a language embodying all of them would presumable impose such a cognitive load on the user that it would be unusable. One could still imagine uses for such an artificial language, for instance in machine translation, whereby a text in a natural language would be translated into such an artificial language, with the result that all semantic

\footnotetext{
${ }^{3}$ As with the difference between Korean and Esperanto noted in footnote 2, Korean and Gokana are not exactly parallel. In (16), use of the nonreflexive pronoun $k u$-lul would also be possible on the interpretation where the two subjects are coreferential. Since Korean uses a reflexive pronoun that can also have a clause-mate antecedent, (16) can also, at least for some speakers, get the interpretation "Yongho believes that Minca loves herself." This is not possible for Gokana sentence (13), since the logophoric suffix can only be used where coreferential noun phrases are separated by a clause boundary.
} 
information would be available for subsequently retranslating into some other natural language. But even if this is feasible-note, for instance, that an English text will often provide no clue as to how an object is being carried, thus giving the translation device no guide in selecting the appropriate body part that is doing the carrying-then it belongs to the realm of mechanical data processing, not to that of an international language. And as we have shown, Esperanto does not meet this ideal of making every semantic distinction possible even in every known language, showing clear biases towards the semantic distinctions made in European languages.

\section{Sociological factors}

In section 3 I will use the term "variation" in two senses. The firsts, "grammatical variation", will refer to the availability of more than one grammatical construction with more or less the same meaning, for instance active and passive voice in English. The second, "sociological variation", refers to the use of different variants by different social groups, for instance the use of certain vocabulary items by speakers of British versus American varieties of English. As we will see below, when it comes to speaking of variation in Esperanto, it is not always easy to keep the two senses apart

An illustration of this is provided by the basic word order (more accurately: constituent order) within the clause. As is well-known, English has a basic constituent order Subject-Verb-Object(SVO), as in (17). The only variant permitted in the modem language, and that primarily in the spoken language, is OSV, which has the clear effect of topicalizing the object, as in (18). Thus, despite the absence of nominative versus accusative case marking for nonpronominal noun phrases in English, sentences like (17) and (18) are not ambiguous, because of the constraints on constituent order.

(17) The dog saw the cat. 
(18) The cat the dog saw.

In Esperanto, by contrast, there is a case distinction between nominative and accusative, the latter taking the inflection $-n$. And it has been noted explicitly since the work of the creator of Esperanto, Ludwik Zamenhof, that this leads to the possibility in Esperanto of varying constituent order without changing the basic meaning, so that one can have both SVO as in (19), and OVS as in (20), and indeed any permutation of the three major constituents of this sentence.

$\begin{array}{lllll}\text { La } & \text { hundo } & \text { vid-is } & \text { la } & \text { kato-n. } \\ \text { the } & \text { dog } & \text { see-PST } & \text { the } & \text { cat-ACC }\end{array}$

(20) La kato-n
the cat-ACC
'The dog saw the cat'

vid-is la hundo.

see-PST the dog

The question arises: What is the function of such constituent order variation in Esperanto?

Interestingly, two radically different answers are given in the literature. First, the variation could be exploited as sociological variation. More specifically, the different variants could be made available to speakers of different languages according to the basic constituent order of their own language. Thus, speakers of an SOV or basically SOV language like Korean (of. (21)) would use the order SOV in Esperanto, to give la hundo la katon vidis, while speakers of Malagasy, the basically VOS language of Madagascar, would use the order VOS in Esperanto to give vidis la katon la hundo. The case inflection on katon and its absence on hundo permits unequivocal retrieval of the grammatical relations.

(21) $\mathrm{Ku}$ kae-ka $\mathrm{ku}$ Koyangi-lul
the dog-NOM the cat-ACC
'The dog saw the cat' 
Essentially this position is taken by Janton (1993:73), who writes:

Today, it is perfectly reasonable to argue that Esperanto syntax allows Japanese speakers to render 'the dog saw the cat' as la hundo la katon vidis or Arabic speakers to say vidis la hundo la katon, just as they would in their own languages, as long as rules of clarity and comprehensibility are observed.

It should be noted that just such variation in constituent order, depending on the word order of the speaker's native language, was noted for Hawaiian Pidgin English (Bickerton \& Givon 1976), which served the function of an interethnic means of communication in the early days of Hawaii's plantation economy.

However, Janton's position seems to be something of a minority position, and my suspicion is that someone who consistently or preferentially used a constituent order like SOV would be judged at least odd by mainstream Esperantists. More frequent are statements like that of Wells $(1975: 22):^{4}$

Although the commonest word order is, as in English, subjectpredicate-object, any order of these elements is in fact possible: for varied emphasis or for stylistic effect, 'Bill hit John' may be Vilcjo bat is Johanon, Vilcjo Johanon batis, Johanon Vilcjo batis, batis Johanon Vilcjo, or batis Vilcjo Johanon.

Wells is thus claiming that constituent order in Esperanto is an instance of grammatical rather than sociolinguistic variation. However, my brief and far from exhaustive survey of the literature on Esperanto grammar, though turning up various statements similar to Wells ${ }^{1}$, has not uncovered any detailed statement of what the principles are that determine this variation. Certainly different

\footnotetext{
${ }^{4}$ I have changed the typefaces used by Wells to match those in the rest of this paper. The morphological structure of the relevant words is: bat - is 'hit-PST', Johano $-n$ "John-ACC'.
} 
languages of the world make very different use of word order for purposes of emphasis. In Hungarian, for instance, the emphasized constituent is placed in preverbal position, as in (23) in comparison with (22), a possibility that is not available, certainly not for object noun phrases, in English.

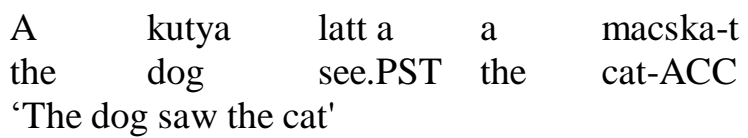

(23) A kytya a macska-t latta.

'The dog saw the cat.'

This possibility is not available in, for instance, English or French. So we are left with wondering whether there are specific rules for the interpretation of constituent order variation in Esperanto, or whether perhaps some sociological variation is to be introduced, for instance with native speakers of Hungarian, but not of English or French, using la hundo la katon vidis to emphasize the object-but this would seem to presuppose, rather unrealistically, that speakers of Esperanto would know the word order rules of every native language spoken by other Esperanto speakers.

The above observations, while serving to illustrate an empirical problem in the evaluation of variation internal to Esperanto, also lead to a more general consideration of the role of variation in an international language, more specifically to the extent to which sociolinguistic variation should be tolerated within such a language, even more specifically the role of variation that is tied to the native language of the speaker. In speaking of natural languages, one can make a distinction between those that have a single standard, which is usually expected to be emulated by nonnative speakers wishing to acquire the language, versus those that have plural standards and, at least typically, admit a fair amount of leeway in nonnative speakers' acquisition of the language. French is a good example of the former the standard language, based essentially on that of educated 
Parisians, is the accepted standard, and while recent years have seen some relaxation in the acceptance of other varieties, both native and normative, it is nonetheless the case that the nonnative speaker will be expected to aim at this standard, and will be judged according to the degree of attainment of this model. English, by contrast, is a good example of a language with plural standards: In addition to the recognized major varieties British and American English, there are numerous other national varieties that are widely used and recognized in international communication, including not only varieties used in countries where English is the major first language, such as Australia, but also in countries where English is not the major first language, such as India. For purposes of international communication, most speakers of Indian English do not feel pressure to assimilate to a first-language variety, so long as they can make themselves understood. English is thus a language whose native speakers, especially those involved in international communication, are in general tolerant of a wide range of variation and recognize the existence of a number of nonnative speaker varieties.

In principle, such variation can have both advantages and disadvantages. A disadvantage for users of the language is that they must at least be able to understand passively the several varieties used in international communication, while learners have the problem of deciding which variety they should take as their model. ${ }^{5}$ The advantage is that nonnative speakers can concentrate on conveying their message, rather than on the finer points of pronunciation or stylistics that are unlikely to be noted by those who are not native speakers, and will anyway be evaluated differently by native speakers of different national varieties. Overall, this advantage seems to outweigh the disadvantages. Indeed, one of the reasons for the success of English as an international language is precisely its tolerance of sociological variation: It is easier to

\footnotetext{
${ }^{5}$ I remember teachers of English in the former Soviet Union telling me in the 1970s that they insisted on teaching British rather than American English because British English, unlike American English, has a well-defined standard (R[eceived] P[ronouncuation]).
} 
become accepted as a speaker of English than it is, for instance, to become accepted as a speaker of a language with a well-defined native-speaker standard. English as an international language has in some respects started to live a life of its own independent of that of native-speaking English communities. I have experienced a number of occasions when nonnative speakers of English have rejected my opinions as to what constitutes correct English, precisely on the grounds that English as an international language no longer belongs exclusively to its native speakers. Indeed, one could even argue that the success of a language as an international language may depend precisely on the willingness of first-language and established second-language speakers to be tolerant of variation introduced by nonnative speakers. Arguably, the attempts to "purify" Latin initiated by Alcuin during the reign of Charlemagne in the late eighth and early ninth centuries and by Erasmus in the late fifteenth and early sixteenth centuries served only to make Latin even more the language of a small elite, and ultimately to its replacement as an international language.

But English has potential as an international language not only because of the existence of plural standards. English is also the language of international communication irrespective of the cultural or other allegiance of its user. While most native speakers are members of Anglo- Saxon cultures, English is widely used as a second language by those who do not belong to such cultures, even by those who do not belong to such cultures, even by those who reject the values of those cultures. It is, for instance, considered perfectly acceptable by those who wish to denounce American imperialism to do so using the English language. English has thus, within the space of a few decades, become a language of international communication divorced from the cultures of native speakers of the language. This contrasts sharply, for instance, with the way in which French is perceived. Learning the French language is typically intimately tied up with learning about French culture, indeed advanced courses are usually styled "langue et civilisation", literally language and civilization', although at least as a native 
speaker of English I feel a better English rendering would be 'language and culture'.

Let us return to the comparison with Esperanto. As noted in section 1. one of the important claims made about Esperanto is that it is not the language of any particular people or nation, and therefore is a truly international language. However, the earlier part of this section has argued that English as an international language is increasingly becoming a language divorced from the cultural roots of its native speakers. English has for a long time not by any stretch of the imagination been the language of a single national community and, with the increase in the number of members of different communities acquiring the English language but without any attempt to assimilate to an English-speaking community, the effects of this phenomenon of a divorce between speakers and community is increasing. There simply is no single English-speaking community. Yet this is precisely one of the advantages claimed for Esperanto. In the meantime, how is the situation developing with Esperanto?

Maxwell (1989: 116) notes that "speakers of Esperanto generally show the influence of their mother tongue in their use of Esperanto, but this does not interfere with communication". But this is in the discussion of a very restricted kind of variation, namely the principle that an artificial language should "permit allophonic variation, but no neutralization of contrasts" (Maxwell 1989: 111). ${ }^{6}$ This is certainly considerably less than the kind of native-language determined variation in constituent order envisaged by Janton. Maxwell (1989: 116) does, however, note a number of other variants that are not accepted by all Esperantists, such as the synthetic passive mangitas 'is eaten' alongside the traditional analytic estas

\footnotetext{
${ }^{6}$ And note that even native-speaker varieties of English have pronunciation variation that varies well beyond allophony. For instance, most speakers in England make no distinction between shore and Shaw (some further adding sure), while most Americans distinguish these; conversely, many Americans do not have a pronunciation distinction between Shaw and shah, whereas most speakers in England do make a distinction.
} 
mangita, or the introduction of the neologism far as a preposition to introduce passive agents.

But perhaps the most important fact is not the existence or absence of such variation, but rather the fact, already introduced in the previous passage by the use of the term Esperantist, that learning Esperanto is, at least for most of those who learn the language well, not merely the learning of a language but rather adherence to a movement. Forster (1982:17-18) says:

However, the degree to which it is possible to use Esperanto without being a member of the organised movement is severely limited. It is possible to buy and borrow Esperanto books, or to maintain personal contacts already established through Esperanto; but it is not possible to form new contacts effectively without being a member of some kind of association.

Thus, although Esperanto is not the language of any particular ethnic or national community, it is nonetheless the language of a community, in the words of Wood (1979) "a voluntary non-ethnic and non-territorial speech community". And this community has mechanisms, both formal and informal, for the evaluation of language use and language innovation. Of these, Piron (1989: 141) suggests that the informal mechanisms are more potent than the formal ones, as with the use of televido 'television' rather than the officially recommended televizio; more generally, according to Piron:

It appears that the speakers of Esperanto have developed a sense of what can and what cannot be assimilated into the language. They have a subtle feeling of how it should evolve, even if they would be at a loss to define it.

In other words, surprising as it may seem, English has to a large extent abstracted itself from any particular community, whereas 
Esperanto has acquired one.

\section{Conclusions}

Perhaps the single most general conclusion one can make about the international language question in the world today is that English has become the international language par excellence. The reasons why this has come about are perhaps not so obvious as they might seem. English- speaking countries have not in general invested heavily in the teaching of English overseas, certainly not in the way that France provides financial support for the teaching of the French language (and culture). And while the economic and political power of the USA, and to a certain extent of some other English-speaking countries, can be seen as a factor in the rise of English as an international language, it is certainly not generally the case that international languages correspond to economic or political power The nineteenth century, when French was the main language of international communication, was hardly a period of French economic or political might, and the Russian gentry who spoke French as well as if not better than they spoke Russian certainly did not espouse French republicanism.

In the comparison between English and Esperanto, I have argued that Esperanto cannot claim neutrality among the languages of the world in terms of its grammatical structure or vocabulary, both of which are clearly European, in much the same way as English vocabulary and grammar can be characterized as European. There are even individual areas, such as relative clauses, where Esperanto turns out to be even more Eurocentric than English is. However, Euro-centrism does not seem to have been a practical barrier to the acceptance of English as an international language, as can be seen in its widespread use as an international language in, for instance, East Asian countries like Korea. In sociological terms, independence from any particular community has come to an increasing extent to characterize English, while surprisingly the relative success of 
Esperanto as an artificial international language has led to the formation of a community. Nowadays, English, the natural language, is arguably more community-independent than is Esperanto, the artificial language. The study of international languages is fraught with surprises; for this very reason, it is an interesting theoretical study, in addition to its practical importance in international communication.

\section{References}

Bickerton, Derek \& Givon, Talmy. (1976). 'Pidginization and syntactic change: from SXV and VSX to SVX'. In Sanford B. Steever, Carol A. Walker, \& Salicoco S. Mufwene (eds): Papers from the Parasession on Diachronic Syntax, 9-39. Chicago: Chicago Linguistic Society.

Comrie, Bernard. (1989). Language universals and linguistic typology. $2^{\text {nd }}$ ed. Oxford: Blackwell/Chicago: University of Chicago Press.

Comrie, Bernard. Forthcoming. 'How exotic are European languages: The case of the relative clause'.

In Ekkehard Konig \& Martin Haspelmath (eds.): EURPTYP, vol. 10. Berlin: Mounton de Gruyter.

Eco, Umberto. (1993). La ricerca della lingua perfetta [The search for the perfect language ].(Fare l'Europa.) Roma/Bari: Laterza.

Forster, Peter G. (1982). The Esperanto movement. (Contributions to the Sociology of Language, 32.) The Hague/Paris/New York: Mouton.

Grimes. Barbara F. (ed.). (1992). Ethnologue: Languages of the world. $12^{\text {th }}$ ed. Dallas: Summer Institute of Linguistics.

Hyman, Larry M. \& Comrie, Bernard. (1981). 'Logophoric reference in Gokana'. Journal of African Languages and Linguistics 3:19-37)

Janton, Pierre. (1993). Esperanto : Language, literature, and community. Albany: State University of New York Press

Jones, B. J. \& Rhie, Gene S. (1991). Standard English-Korean 
Korean-English dictionary for foreigners. Seoul and Elizabeth, NJ: Hollym.

Kraus, Michael. (1992). "The world's languages in crisis". Language 68: 4- 10 .

Maxwell, Dan. (1989). 'Principles for constructing planned languages'. In Schubert (ed.), 101-119.

Piron, Clause. (1989). 'A few notes on the evolution of Esperanto'. In Schubert (ed.), 129-142.

Schubert, Klaus (ed.). (1989). Interlinguistics: Aspects of the science of planned languages. (Trends in Linguistics: Studies and Monographs, 42). Berlin: Mouton de Gruyter.

Sohn, Ho-min. (1994). Korean. (Routledge Dscriptive Grammars.) London/New York: Routledge.

Wells. J.C. (1974). Concise Esperanto and English dictionary. (Teach Yourself Books.) London: Hodder \& Stoughton/Lincolnwood, IL NTC.

Wood, Richard E (1979). 'A voluntary non-ethnic and non-territorial speech community'.

In William Francis Mackey \& Jacob Ornstein (eds.) :Sociolinguistic studies in language contact: Methods and cases. (Trends in Linguistics, Studies and Monogrphs, 6.) The Hague/Paris/New York: Mouton.

World almanac and book of facts 1995.1994. Mahwah, NJ: World Almanac. 